\title{
Modificações dos Componentes de Parede Celular do Melão 'Orange Flesh' Submetido a Tratamento Pós-colheita com Cálcio
}

\author{
Eduardo V. de B. Vilas Boas* , Adimilson B. Chitarra and Josivan B. Menezes \\ Universidade Federal de Lavras, Dep. Ciências dos Alimentos, C.P. 37, 37200-000, Lavras - MG, Brazil
}

\begin{abstract}
The purpose of this work was to study the structural changes of the cell wall during the storage of 'Orange Flesh' melon submitted to postharvest treatment with $\mathrm{CaCl}_{2}$. The content of cellulose, hemicellulose, pectic substances and their degree of esterification, proteins and calcium was determined in the cell wall of the flesh of the fruits stored under ambient temperature and refrigeration. The hot-water treatment for immersion in $\mathrm{CaCl}_{2}$ of 'Orange Flesh' melons stored under ambient temperature determinated, apparently, an increase in the concentration of calcium bound to cell wall of the flesh of the fruits, besides partially inhibiting the breakdown of pectic substances and their de-esterification and to promoting the solubilization of proteins of the cell wall, although it did not influence the changes of the cell wall compounds except that of the polyuronides, in the fruits stored under refrigeration at $6^{\circ} C$. In spite of calcium treatment, the storage of 'Orange Flesh' melon for 28 days at ambient temperature showed a decrease in the levels of cellulose and protein and a substantial de-esterification of the pectins, although it did not affect, apparently, the content of hemicellulose and promoted a relative increase in the polyuronides and calcium bound to cell wall. The fruits stored under refrigeration showed a few changes of the cell wall compounds, despite the fact that a reduction in the degree of esterification was noticed during the 31 days of storage.
\end{abstract}

Key words: melon cell wall, melon postharvest, calcium postharvest treatment

\section{INTRODUÇÃO}

O melão é um fruto tropical de alto valor comercial, apreciado por suas características sensoriais tanto no mercado interno, quanto no externo. Um incremento na demanda deste produto tem sido observado nos últimos anos, embora técnicas que visem o prolongamento de sua vida pós-colheita ainda sejam incipientes, frente a um mercado consumidor distante e extremamente exigente. Os melões nobres ("cantaloupes") são os preferidos pelo mercado norte americano devido às suas peculiaridades de sabor, coloração, valor nutritivo (fonte de vitamina A) e uniformidade. O melão 'Orange Flesh', que se caracteriza por um requintado paladar, tem se apresentado com grande aceitação nos mercados interno (São Paulo) e externo (Europa), embora apresente uma vida de prateleira curta, em comparação com outras cultivares.

A vida pós-colheita de frutos está intimamente relacionada com as modificações sofridas na parede celular. A parede celular constitui-se de uma complexa associação entre carboidratos (celulose, hemicelulose e substâncias pécticas), proteínas, lignina, água e substâncias incrustantes como cutina e suberina, além de certos compostos inorgânicos, como o cálcio (Showalter, 1993). O cálcio tem recebido considerável atenção nos últimos anos face aos seus desejáveis efeitos no retardo da senescência e controle de desordens fisiológicas em frutos e hortaliças (Poovaiah, 1986). A sua utilização na forma de $\mathrm{CaCl}_{2}$ na pós-colheita tem se mostrado como um método em potencial de consevação pós-colheita de frutos (Alonso, Rodriguez \& Canet, 1995; Scalon, 1996; Vilas Boas et al., 1998). Ele se liga às substâncias pécticas da

\footnotetext{
* Autor para correspondência
} 
parede celular, dando origem aos pectatos de cálcio, agentes cimentantes tão importantes na adesão célula a célula e manutenção da integridade estrutural (Salunke, Bolin \& Reddy, 1991). Os íons $\mathrm{Ca}^{2+}$ agem, provavelmente, como pontes iônicas entre resíduos de ácido galacturônico carregados negativamente, formando uma estrutura estável denominada "egg box" (Brett \& Waldron, 1990), sendo que a metil esterificação limita a capacidade de associação entre pectinas e cálcio, pela alteração da distribuição de carga da molécula (Maness, Ryan \& Mort, 1990; Kim \& Carpita, 1992). As extensinas, principais glicoproteínas da parede celular (Keller, 1993), encontram-se, provavelmente, associadas ionicamente e/ou covalentemente aos componentes da parede celular, principalmente, às substâncias pécticas (Qi et al., 1995). Oscilações no teor de cálcio na parede celular também podem influenciar esta associação, embora ela esteja sob restrito controle desenvolvimental (Cassab e Varner, 1988; Showalter, 1993).

Visto que a preservação Pós-colheita de melões constitui-se numa preocupação atual e que estudos que visem colocar em estreita analogia a constituição, bem como os mecanismos associados à degradação da parede celular, e os processos relativos ao amadurecimento $\mathrm{e}$ senescência destes frutos careçam de detalhes, o presente trabalho teve como objetivo a determinação das modificações dos componentes de parede celular de melões 'Orange Flesh', submetidos a tratamento hidrotérmico com $\mathrm{CaCl}_{2}$, durante o seu armazenamento.

\section{MATERIAL E MÉTODOS}

Os frutos do meloeiro 'Orange Flesh' foram provenientes de experimentos instalados no Polo Agrícola Mossoró-Assu, RN. Após colheita, foram transportados para o laboratório de Fisiologia e Bioquímica Pós-colheita do Departamento de Ciências dos alimentos da UFLA, onde foram submetidos a imersão em solução aquosa de $\mathrm{CaCl}_{2}$ a $2 \%$, a $50^{\circ} \mathrm{C}$ por 20 min. Os frutos considerados como controle não sofreram este tratamento. Em seguida, um grupo foi armazenado em sala com temperatura ambiente e analisado a cada 7 dias $(7,14,21$ e 28 dias). Um segundo grupo foi mantido sob refrigeração a $6^{0} \mathrm{C}$ e $85 \pm 5 \%$ de umidade relativa e analisado aos 17 e 31 dias de armazenamento. Foi realizada uma caracterização dos frutos no tempo zero, antes de qualquer tratamento.

$\mathrm{O}$ delineamento experimental foi inteiramente casualizado em esquema fatorial 2 X 5, onde os fatores estudados foram $\mathrm{o}$ cálcio nos seguintes níveis: 0 e $2 \%$ de $\mathrm{CaCl}_{2}$ e o armazenamento, em cinco períodos $(0,7,14,21,28$ dias $)$ para os frutos sob temperatura ambiente, e $2 \times 3$, $(0$ e $2 \%$ de $\mathrm{CaCl}_{2} ; \quad 0, \quad 17$ e 31 dias de armazenamento) para os frutos mantidos sob refrigeração, com três repetiçòes. Cada parcela experimental foi proveniente da parede celular extraída a partir de 10 frutos.

Foram realizadas as seguintes avaliações:

Extração do material de parede celular: a polpa de fruto foi congelada em nitrogênio líquido, embalada em sacos transparentes de polietileno de baixa densidade $(27,0 \mathrm{~cm} \mathrm{X} 31,0$ $\mathrm{cm})$ com fecho hermético e mantida a $-18^{0} \mathrm{C}$ até ser submetida ao processo de extração.

A parede celular foi extraída do tecido mesocárpico como descrito por Mitcham e Mc Donald (1994), com poucas modificações. O mesocarpo $(350 \mathrm{~g})$ foi triturado em liquidificador com etanol $80 \%(350 \mathrm{ml})$. O resíduo foi lavado com tampão fosfato de potássio $50 \mathrm{mM}, \mathrm{pH} 6,8$ (700ml), seguido de PAW (fenol: ácido acético: água 2:1:1) (300 ml) e novamente com o mesmo tampão fosfato $(700 \mathrm{ml})$. A parede celular isolada foi submetida ao teste com $\mathrm{KI} / \mathrm{I}_{2}$ para verificar a ausência de amido. A parede celular foi sucessivamente lavada com clorofórmio:metanol-1:1 V/V - (250ml) e acetona (3 porções de $200 \mathrm{ml}$ ), seguida de secagem sob vácuo à temperatura ambiente.

Determinação de Cálcio : o cálcio ligado foi determinado usando-se $100 \mathrm{mg}$ de material de parede celular, pelo método de Jones e Isac (1969). 
Celulose: $2 \mathrm{mg}$ de parede celular foram digeridos em $3 \mathrm{ml}$ de $\mathrm{H}_{2} \mathrm{SO}_{4} \quad 72 \%$ e concentração de açúcares neutros (celulose + hemicelulose) foi determinada pelo método da antrona, segundo Dische (1962). O teor de celulose foi obtido por diferença [(celulose + hemicelulose) - hemicelulose)].

Hemicelulose: $2 \mathrm{mg}$ de parede celular foram solubilizados em $1 \mathrm{ml}$ de ácido trifluoracético (TFA $2 \mathrm{~N}$ ) a $120^{\circ} \mathrm{C}$ e filtrados em papel de filtro. Em seguida, o filtrado foi diluído em água destilada e os açúcares neutros determinados através do método da antrona (Dische, 1962).

Poliuronídeos: $2 \mathrm{mg}$ de parede celular foram digeridos em $3 \mathrm{ml}$ de $\mathrm{H}_{2} \mathrm{SO}_{4} 72 \%$ e o teor de ácidos urônicos foi doseado pelo método do meta-fenil-fenol (Blumenkrantz \& AsboeHansen, 1973).

Grau de esterificação da pectina (GE): $2 \mathrm{mg}$ de parede celular foram incubados em $1 \mathrm{ml} \mathrm{de}$ boridreto de sódio (10mg / $\mathrm{ml}$ de metanol 50\%) por uma noite à temperatura ambiente. Foram em seguida neutralizados com ácido acético glacial até cessar a efervecência $( \pm 4 \mathrm{ml})$ e lavados 3 vezes com ácido acético:metanol (1:9) e 3 vezes com metanol, com evaporação a cada etapa, segundo Lurie et al. (1994). As amostras foram digeridas com $\mathrm{H}_{2} \mathrm{SO}_{4} 72 \%$ e o teor de ácidos urônicos determinado. A diferença no conteúdo de ácidos urônicos entre as amostras antes e depois da redução com boridreto, representa a quantidade de ácido urônico que continha metil ésteres. GE $=$ [(Ac. urônicos antes da redução - Ac. urônicos após redução) / Ac. urônicos antes da redução] x 100

Proteína: determinada em 100mg de parede celular, pelo método de micro-Kjeldahl, segundo AOAC (1990).

\section{RESULTADOS E DISCUSSÃO}

Os melões 'Orange Flesh' armazenados à temperatura ambiente e submetidos ao tratamento pós-colheita com $\mathrm{CaCl}_{2}$ apresentaram uma maior concentração de cálcio ligado à parede celular extraída da polpa que os frutos controle, aos 7, 14 e 21 dias, o que demonstra a eficiência de absorção deste mineral, quando aplicado hidrotermicamente, por imersão, na forma de sal com o $\mathrm{Cl}$ ( $\mathrm{p}<$ 0,01). Pulverizações e imersões de $\mathrm{CaCl}_{2}$ retardam o amaciamento e senescência de frutos, visto que o cálcio desempenha um importante papel na manutenção da estrutura de frutos através de sua associação com substâncias pécticas (Poovaiah, 1986; Salunke, Bolin \& Reddy, 1991; Alonso, Rodriguez e Canet, 1995; Scalon, 1996; Vilas Boas et al., 1998). Maçãs submetidas a infiltração com $\mathrm{CaCl}_{2}$, sob diferentes pressões, apresentaram um maior teor de cálcio na polpa e na casca, após 90 dias de armazenamento a $0^{\circ} \mathrm{C}$, quando comparadas com frutos controle, o que resultou numa maior firmeza daqueles frutos (Poovaiah, 1986). Observou-se um aumento nos níveis de cálcio ligado em função do tempo de armazenamento, comportamento este, semelhante para ambos grupos de frutos (submetidos ou não ao tratamento com $\mathrm{CaCl}_{2}$ ) (Figura 1). Lester e Dunlap (1985) reportaram um comportamento relativamente constante do teor de cálcio ligado em melões 'Perlita', durante sua maturação, contraditório ao verificado no presente trabalho, embora a cultivar utilizada tenha sido outra.

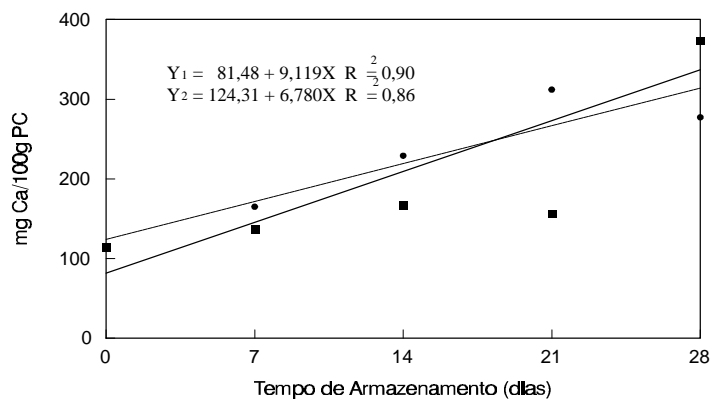

Figura 1 - Curva de Cálcio ligado à parede celular de melão 'Orange Flesh' armazenado sob temperatura ambiente $\left(\mathrm{Y}_{1}-\mathbf{\square}\right.$ - controle; $\mathrm{Y}_{2}$---• - imersão em $\mathrm{CaCl}_{2}$ ) 
O tratamento com cálcio não afetou os níveis de celulose e hemicelulose da parede celular de melão 'Orange Flesh'. Os teores de celulose apresentaram uma ligeira tendência de queda enquanto os de hemicelulose não apresentaram alterações aparentes com o armazenamento (Figura 2).

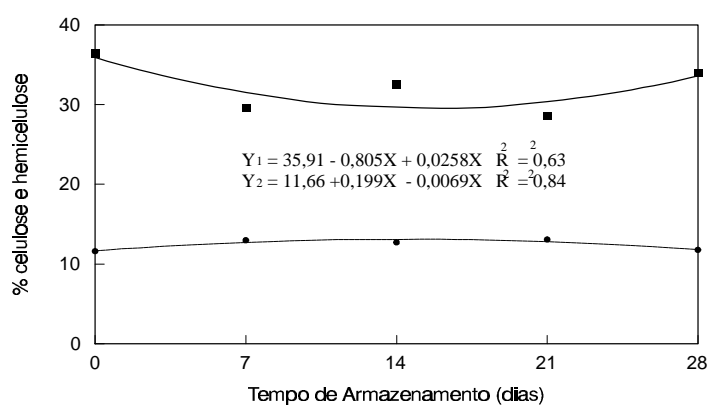

Figura 2 - Curva de Celulose e Hemicelulose da parede celular de melão 'Orange Flesh' armazenado sob temperatura ambiente $\left(\mathrm{Y}_{1}-\mathbf{-}\right.$ - celulose; $\mathrm{Y}_{2}$--- - hemicelulose; médias de controle e imersão em $\mathrm{CaCl}_{2}$; interação tratamento $\mathrm{X}$ tempo de armazenamento não significativa $-\mathrm{p}<0,05)$

Os frutos tratados com $\mathrm{CaCl}_{2}$ apresentaram uma maior concentração de poliuronídeos na parede celular que os frutos controle, durante todo o período de armazenamento (7, 14, 21 e 28 dias) $(\mathrm{p}<0,01)$, o que sugere a ligação do cálcio às substâncias pécticas com possível efeito na manutenção da estrutura celular. O retardo na senescência de frutos tratados com cálcio se dá, principalmente, pela formação de pectatos de cálcio, devido às ligações cruzadas entre cadeias de galacturonanas e cálcio na parede celular (Salunke, Bolin \& Reddy, 1991). Os íons $\mathrm{Ca}^{2+}$ agem, provavelmente, como pontes iônicas entre resíduos de ácido galacturônico carregados negativamente, formando uma estrutura estável denominada "egg box" (Brett \& Waldron, 1990). Observou-se um relativo incremento dos níveis de poliuronídeos paralelo ao tempo de armazenamento, provavelmente, devido a redução de outros constituintes da parede celular (Figura 3).

$\mathrm{O}$ tratamento com $\mathrm{CaCl}_{2}$ influenciou positivamente $\mathrm{o}$ grau de esterificação das substâncias pécticas de melão "Orange Flesh".
Os frutos tratados com cálcio apresentaram um grau de esterificação médio superior aos controle $(\mathrm{p}<0,01)$, o que permite deduzir, mais uma vez, a eficiência do cálcio na manutenção da arquitetura péctica da parede celular, considerando-se que frutos em estádios mais avançados de amadurecimento apresentam menores graus de esterificação. Por outro lado, poderia se esperar que a presença de cálcio na parede celular promovesse a competição entre este mineral e metil ésteres frente a possíveis ligações com as substâncias pécticas, o que redundaria em redução do grau de esterificação.

De acordo com Maness, Ryan \& Mort (1990) e Kim e Carpita (1992), a esterificação limita, aparentemente, a habilidade de pectinas em formar interligações com o cálcio pela alteração da distribuição de cargas da molécula. Observou-se uma nítida redução do grau de esterificação durante o período de armazenamento do melão (Figura 4). Concordantemente, o grau de esterificação tem sido observado reduzir com o amadurecimento de diversos frutos (Batisse; Fils-Lycaon \& Buret, 1994; El-Zoghbi, 1994; Lurie et al., 1994). Esta redução no grau de esterificação observada durante o amadurecimento de frutos tem sido associada à ação desesterificante da pectinametilesterase (PME) que determina a taxa e extensão da hidrólise de substâncias pécticas por poligalacturonase (PG), o que culmina, normalmente, com o aumento da solubilização de substâncias pécticas e amaciamento do fruto. Não obstante, a presença e atividade destas duas enzimas em melão ainda não foram comprovadas.

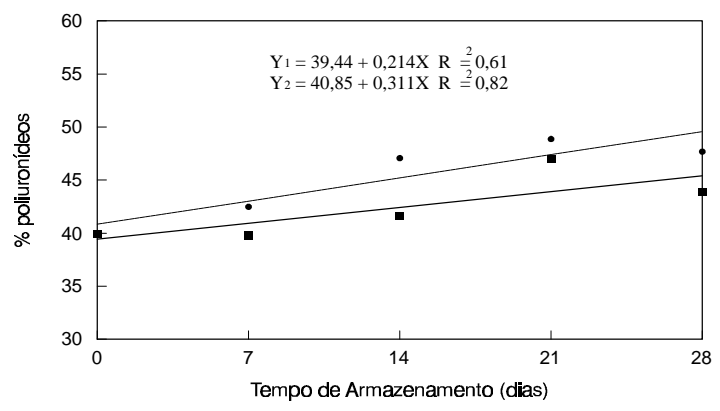

Figura 3 - Curva de Poliuronídeos da parede celular de melão 'Orange Flesh' armazenado sob temperatura ambiente $\left(\mathrm{Y}_{1}\right.$ - $\mathbf{-}$ - controle; $\mathrm{Y}_{2}$--- - imersão em $\mathrm{CaCl}_{2}$ ) 
Foi observado, nos frutos controle, um maior teor de proteínas, quando comparados aos frutos submetidos à imersão com $\mathrm{CaCl}_{2}$, aos 7, 21 e 28 dias de armazenamento $(\mathrm{p}<0,01)$. Pode-se supor que o cálcio ao se ligar com a parede celular tenha competido com possíveis sítios de ligação destas proteínas estruturais. As extensinas, que se caracterizam por apresentarem uma alta proporção de seus aminoácidos como hidroxiprolina, junto com grandes quantidades de serina e lisina, são as glicoproteínas mais bem estudadas da parede celular (Brett \& Waldron, 1990). A presença de lisina, as torna proteínas básicas que interagem, possivelmente, com com blocos pécticos acídicos da parede celular. Contudo, tais interações podem ser reguladas por mudanças no teor de $\mathrm{Ca}^{2+}$ da parede celular (Cassab \& Varner, 1988; Showalter, 1993). Uma redução no teor de proteínas foi observado com o decorrer do armazenamento, sugerindo a solubilização destas proteínas com o amadurecimento do fruto (Figura 5). Tem se tornado claro que as interligações de proteínas da parede celular estão sob restrito controle desenvolvimental (Keller, 1993; Showalter, 1993) e que elas podem fortalecer a parede celular (Bradley; Kjellbom \& Lamb, 1992).

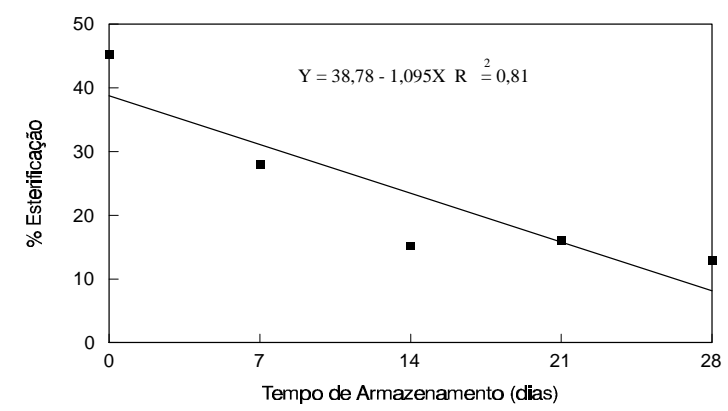

Figura 4 - Curva de Grau de esterificação de substâncias pécticas da parede celular de melão 'Orange Flesh' armazenado sob temperatura ambiente (Y - $\mathbf{\square}$ - média de controle e imersão em $\mathrm{CaCl}_{2}$; interação tratamento $\mathrm{X}$ tempo de armazenamento não significativa $-\mathrm{p}<0,05$ )

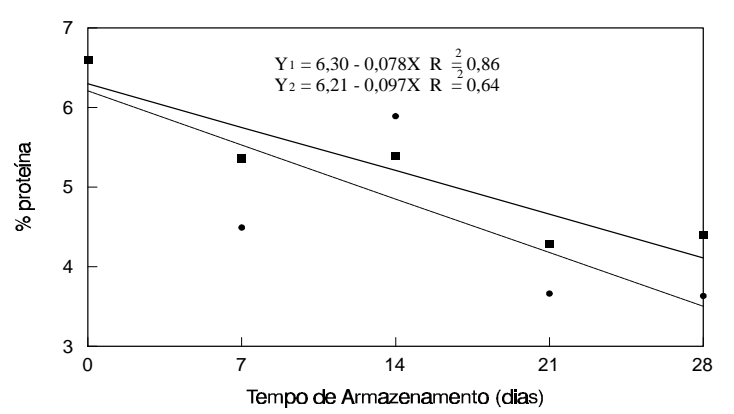

Figura 5 - Curva de Proteínas da parede celular de melão 'Orange Flesh' armazenado sob temperatura ambiente $\left(\mathrm{Y}_{1}-\mathbf{-}\right.$ - controle; $\mathrm{Y}_{2}$-- - imersão em $\mathrm{CaCl}_{2}$ )

Realizou-se, também, um ensaio com 'Orange Flesh' submetido à imersão com $\mathrm{CaCl}_{2} \mathrm{e}$ armazenado sob refrigeração (Tabela 1). Nestas condições não foram observadas modificações estatisticamente significativas $(\mathrm{p}<0,05)$ no teor de cálcio ligado à parede celular da polpa dos frutos controle e submetidos à imersão. Entretanto, da mesma forma que o ensaio anterior, houve um aumento na concentração deste mineral com o tempo de armazenamento. Os teores de celulose e hemicelulose não se alteraram em função do tratamento com cálcio, nem tampouco em função do tempo de armazenamento $(\mathrm{p}<0,05)$. Já as concentrações de pectina nos frutos tratados com $\mathrm{CaCl}_{2}$ mostraram-se superiores às encontradas em frutos controle aos 17 e 31 dias de armazenamento ( $\mathrm{p}<0,01$ ), o que sugere o efeito do cálcio sobre a manutenção da estrutura celular, provavelmente, na forma de pectato de cálcio, embora não tenham sido observadas modificações significativas nas concentrações de cálcio ligado. O grau de esterificação reduziu com o tempo de armazenamento ( $\mathrm{p}<0,01$ ), fenômeno, normalmente, observado duarante o amadurecimento de outros frutos $(14,17,18)$. Contudo não foi influenciado pelo tratamento com cálcio ( $\mathrm{p}<0,05)$, comportamento semelhante sendo observado para as proteínas.

Com base nos resultados apresentados neste trabalho pode-se sugerir o $\mathrm{CaCl}_{2}$ como um tratamento pós-colheita, em potencial, para 
conservação de melões 'Orange Flesh', tendo-se em vista, principalmente, seu efeito na manutenção dos níveis de substâncias pécticas, importantes polissacarídeos da parede celular, cuja solubilização encontra-se, normalmente, associada ao amaciamento e deterioração de frutos.
Os efeitos mais pronunciados do $\mathrm{CaCl}_{2}$ foram observados nos frutos armazenados à temperatura ambiente, provavelmente, porque a esta temperatura os frutos apresentaram um metabolismo mais ativo, o que parece ter propiciado uma maior assimilação do cálcio.

Tabela 1 - Modificações de componentes da parede celular de melão 'Orange Flesh' armazenado sob refrigeração [(média de controle e imersão em $\mathrm{CaCl}_{2}$ (interações tratamento $\mathrm{X}$ tempo de armazenamento não significativa), exceto para poliuronídeos (interação significativa - $\mathrm{p}<0,05)$ ].

Tempo de Armazenamento (dias)

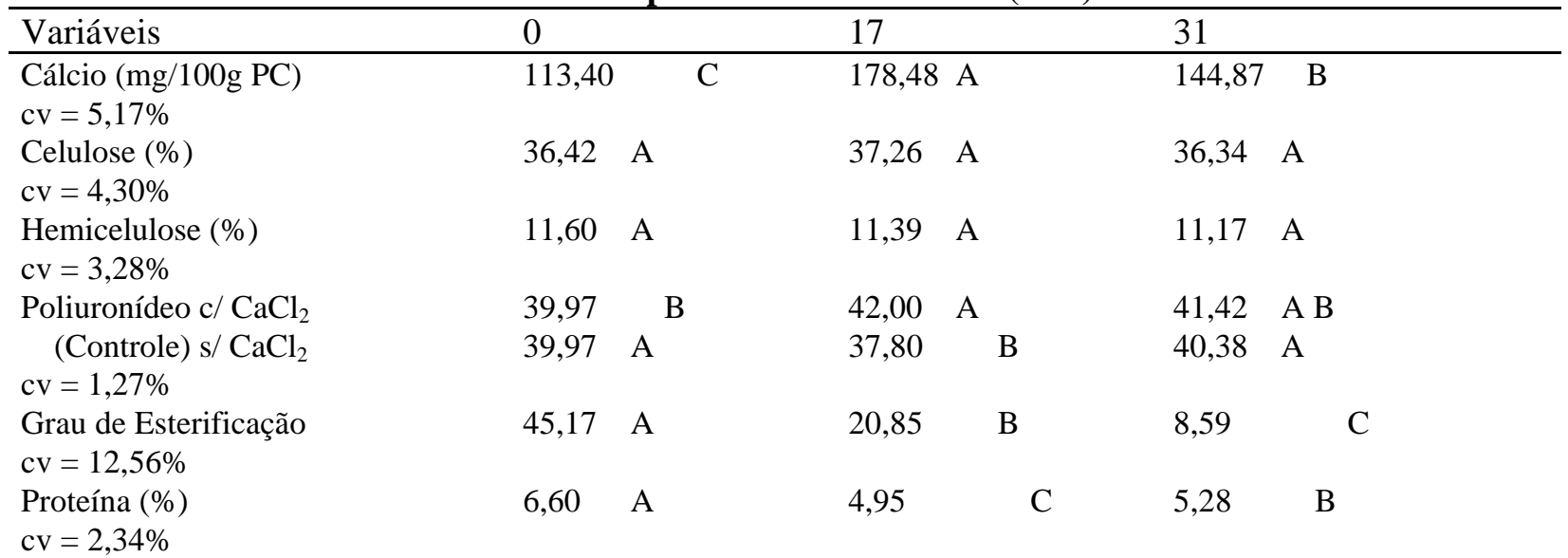

Médias seguidas de mesmas letras na horizontal não diferem entre si, pelo teste de Tukey, ao nível de 5\% de significância.

\section{AGRADECIMENTOS}

Ao CNPq, pela concessão de bolsa de doutorado, ao primeiro autor, durante a execução do projeto.

\section{RESUMO}

O objetivo deste trabalho foi o de estudar as mudanças estruturais da parede celular durante o armazenamento do melão 'Orange Flesh' submetido ao tratamento pós-colheita com $\mathrm{CaCl}_{2}$. Os teores de celulose, hemicelulose, substâncias pécticas e seu grau de esterificação, proteínas e cálcio foram determinados na parede celular da polpa dos frutos armazenados sob temperatura ambiente e refrigeração. $\mathrm{O}$ tratamento hidrotérmico por imersão em
$\mathrm{CaCl}_{2}$ de melões 'Orange Flesh' armazenados sob temperatura ambiente determinou, aparentemente, um incremento na concentração de cálcio ligado à parede celular da polpa dos frutos, além de inibir parcialmente a degradação de substâncias pécticas e seu grau de esterificação e promover a solubilização de proteínas da parede celular, embora não tenha influenciado as mudanças dos compostos da parede celular, a exceção dos poliuronídeos, nos frutos armazenados sob refrigeração a $6^{0} \mathrm{C}$. A despeito do tratamento com cálcio, o armazenamento do melão 'Orange Flesh' por 28 dias à temperatura ambiente determinou uma redução nos teores de proteínas e uma substancial desesterificação das pectinas, embora não tenha afetado, aparentemente, os teores de celulose e 
hemicelulose e promovido um aumento relativo nos poliuronídeos e cálcio ligado à parede celular. Os frutos armazenados sob refrigeração apresentaram poucas mudanças dos compostos da parede celular, a despeito do fato de que uma redução no grau de esterificação tenha sido noticiado durante os 31 dias de armazenamento.

\section{REFERÊNCIAS}

Alonso, J.; Rodriguez, T.; Canet, W. (1995), Effect of calcium pretreatment on the texture of frozen cherries. Role of pectinesterase in changes in the pectic material. J. Agric.Food Chem., 43, 1011-1016

AOAC (1990), Official methods of the Association of the Agricultural Chemists. Washington, 15th Ed., 2v

Batisse, C.; Fils-Lycaon, B.; Buret, M. (1994), Pectin changes in ripening cherry fruit. J.Food Sci., 59, 389-393

Blumenkrantz, N.; Asboe-Hansen, G. (1973), New method for quantitative determination of uronic acids. Anal. Biochem., 54, 484-489

Brett, C.; Waldron, K. (1990). Physiology and biochemistry of plant cell walls. Hyman, London

Bradley, D.J.; Kjellbom, P.; Lamb, C.J. (1992), Elicitor- and wound-induced oxidative crosslinking of a proline-rich plant cell wall protein: a novel, rapid defense response. Cell, 70, 21-30

Cassab, G.I.; Varner, J.E. (1988). Cell wall proteins. Annu Rev. Plant Physiol. Plant Mol. Biol.,.39, 321-53

Dische, Z. (1962). General color reactions. In: Whistleer, R.L.; Wolfram, M.L. ed. Carbohydrate chemistry. Academic Press, New York, pp 475-514

El-Zoghbi, M. (1994). Biochemical changes in some tropical fruits during ripening. Food Chem. 49, 33-37

Jones, J.B.; Isaac, R.A. (1969). Comparative elemental analysis of plant tissue by spark emission and atomic absortion spectrocopy. Agron. J., 61, 393-394

Keller, B. (1993). Structural cell wall proteins. Plant Physiol., 110, 1127-1130
Kim, J.; Carpita, N.C. (1992). Changes in esterification of the uronic acid groups of cell wall polysaccharides during elongation of maize coleoptiles. Plant Physiol., 98, 646-653

Lester, G.E.; Dunlap, J.R. (1985). Physiological changes during development and ripening of 'Perlita' muskmelons fruits. Scientie Horticulturae, 36, 323-331

Lurie, S.; Levin, A.; Greve, L.C.; Labavitch, J. (1994). Pectic polymer changes in nectarines during normal and abnormal ripening. Phytochemistry, 36, 11-17

Maness, N.O.; Ryan, J.D.; Mort, A.J. (1990). Determination of the degree of methyl esterification of pectins in small samples by selective reduction of esterified galacturonic acid to galactose. Anal. Biochem., 185, 346352

Mitcham, E.J.; Mc Donald, R.E. (1994). Cell wall modification during ripening of 'Keit' and 'Tommy Atkins' mango fruit. J. Am. Soc. Hortic. Sci., 17, 919-924

Poovaiah, B.W. (1986). Role of calcium in prolonging storage life of fruits and vegetables. Food Technol., 40, p.86-88

Qi, X.; Behrens, B.X.; West, P.R.; Mort, A.J. (1995). Solubilization and partial characterization of extensin fragments from cell walls of cotton suspension cultures. Plant Physiol., 108, 1691-1701

Salunke, D.K.; Bolin, H.R.; Reddy, N.R. (1991). Storage processing and nutritional quality of fruits and vegetables: fresh fruits and vegetables. v.1. CRC Press, Boca Raton

Scalon, S de P. Q. (1996), Qualidade do morango: efeito do $\mathrm{CaCl}_{2}$ sobre a parede celular e níveis residuais de benomyl. $\mathrm{PhD}$ Thesis, UFLA, MG, Brazil

Showalter, A.M. (1993). Structure and function of plant cell wall proteins. Plant Cell, 5, 9-23

Vilas Boas, E.V. de B.; Botrel, N.; Chitarra, A.B.; Carvalho, V.D. de; Teixeira, G.H. de A. (1998), Modificações de componentes da parede celular do abacaxi submetido ao tratamento com $\mathrm{CaCl}_{2}$, em diferentes temperaturas. Revista Ciência e Agrotecnologia, $\mathbf{2 2}$

Received: September 10, 1997; Revised: September 19, 1997; Accepted: March 12, 1998. 